\title{
Correction to: Human heart shifts from IGF-1 production to utilization with chronic heart failure
}

\author{
Roberta D'Assante ${ }^{1} \cdot$ Raffaele Napoli $^{1}$ - Andrea Salzano ${ }^{2} \cdot$ Carlotta Pozza $^{3}$ - Alberto Maria Marra ${ }^{4}$. \\ Michele Arcopinto ${ }^{1,5}$. Giuseppe Perruolo ${ }^{1}$ - Salvatore Milano ${ }^{6}$ Pietro Formisano ${ }^{1}$. Lavinia Saldamarco ${ }^{5}$. \\ Plinio Cirillo ${ }^{7} \cdot$ Antonio Cittadini $^{1}$
}

Published online: 29 July 2019

(c) Springer Science+Business Media, LLC, part of Springer Nature 2019

\section{Correction to: Endocrine}

https://doi.org/10.1007/s12020-019-01993-y

The original version of this article unfortunately contained a mistake in the first author's family name.
The correct given and family names should be:

Given Name: Roberta

Family Name: D'Assante

The original article has been corrected.

These authors contributed equally: Roberta D'Assante, Raffaele Napoli

The original article can be found online at https://doi.org/10.1007/ s12020-019-01993-y.

Antonio Cittadini

cittadin@unina.it

1 Department of Translational Medical Sciences, Unit of Internal Medicine, Metabolism \& Rehabilitation, Federico II University of Naples, Via S. Pansini n. 5, Bld. 18, 1st floor, Naples 80131, Italy

2 Department of Cardiovascular Sciences and NIHR Leicester Biomedical Research Centre, University of Leicester, Glenfield Hospital, Groby Road, Leicester LE3 9QP, UK

3 Department of Experimental Medicine, Sapienza University of Rome, Rome, Italy

4 IRCCS SDN, Naples, Italy

5 Emergency Department, A Cardarelli Hospital, Naples, Italy

6 Department of Laboratory Medicine, CoreLab, AOUP "P. Giaccone", University of Palermo, Palermo, Italy

7 Department of Advanced Biomedical Sciences, Division of Cardiology, Federico II University of Naples, Naples, Italy 